\title{
HIF-2 $\alpha$ affects proliferation and apoptosis of MG-63 osteosarcoma cells through MAPK signaling
}

\author{
YUQIANG WANG $^{1}$, XIAOHUA WANG ${ }^{2}$, XUETAO SU $^{1}$ and TIANSHENG LIU ${ }^{1}$ \\ ${ }^{1}$ Department of Orthopedic Surgery, The Affiliated Hospital of Logistics College of Chinese People's Armed Police Force, \\ Pingjin Hospital, Tianjin 300162; ${ }^{2}$ Department of Neurological Intensive Care Unit, Tianjin Huanhu Hospital, \\ Tianjin 300060, P.R. China
}

Received October 14, 2016; Accepted January 18, 2017

DOI: $10.3892 / \mathrm{mmr} .2017 .6243$

\begin{abstract}
The present study explored the mechanism of hypoxia-inducible factor (HIF)- $2 \alpha$ in proliferation and apoptosis of the osteosarcoma cell line, MG-63. Cells were treated with small interfering RNA (siRNA) against HIF-2 $\alpha$ (silenced group) or without siRNA (control group). Cell viability of MG-63 in the silenced and the control groups was determined by MTT assay; cell apoptosis was measured by flow cytometry; the expression of HIF-2 $\alpha$ and mitogenactivated protein kinase (MAPK)-p38 were measured by western blotting. According to MTT assay, $48 \mathrm{~h}$ after siRNA transfection, compared with the control group, cells in the silenced group significantly declined in quantity and the number of apoptotic cells increased significantly. The expression of HIF-2 $\alpha$ and MAPK-p38 were significantly decreased $(\mathrm{P}<0.05)$. In conclusion, knockdown of HIF-2 $\alpha$ in the osteosarcoma cell line reduced the proliferation of cancer cells and increased apoptosis. These effects likely occurred through the MAPK-p38 signaling pathway.
\end{abstract}

\section{Introduction}

Osteosarcoma, or osteogenic sarcoma often occurs in children or adolescents $<20$ years old. It has a high degree of malignancy, and its early stage clinical symptoms are usually not obvious $(1,2)$. Its prognosis is poor with relatively low median survival time and 5-year survival rate. With the optimization of therapy for osteosarcoma, the 5-year survival rate has increased from 20 to $60 \%$ and the rate of limb salvage treatment has also markedly increased (3). Osteosarcoma is the most common solid tumor among primary bone malignancies. It has a high degree of malignancy, grows rapidly, and is

Correspondence to: Dr Yuqiang Wang, Department of Orthopedic Surgery, The Affiliated Hospital of Logistics College of Chinese People's Armed Police Force, Pingjin Hospital, 220 Chenglin Road, Hedong, Tianjin 300162, P.R. China

E-mail:wxso73@163.com

Key words: osteosarcoma, HIF-2 $\alpha$, apoptosis likely to create a low-oxygen environment within the tumor, causing increased expression of hypoxia-inducible factor (HIF). According to some studies, HIF plays an important regulatory role in tumor angiogenesis, energy metabolism, invasion, metastasis, and many other biological processes. Furthermore, HIF is closely related to processes such as chemotherapy and tumor resistance (3-5). In cardiovascular diseases, HIF may be associated with the reperfusion process of myocardial infarction. Despite several studies on HIF at present, there are limited studies on the specific role of HIF-2 $\alpha$ in osteosarcoma $(6,7)$. Based on previous research, the aim of the present study was to further explore how HIF- $2 \alpha$ gene silencing effects proliferation, metastasis, invasion, and other aspects of the osteosarcoma cell line MG-63, through the small interfering RNA (siRNA) gene silencing technique.

\section{Materials and methods}

Materials. DMEM medium (Sigma, St. Louis, MO, USA); pancreatic enzymes for cell dissociation (Sigma); fetal bovine serum (FBS; Sigma); MTS solution (Promega Corp., Madison, WI, USA); rabbit anti-human HIF-2 $\alpha$ antibody (Abcam, Cambridge, MA, USA), vascular endothelial growth factor polyclonal antibody, rabbit anti-human extracellular signal-regulated kinase (Erk) antibody and rabbit anti-human phosphorylated Erk (p-Erk) antibody. Mouse anti-human GAPDH antibody, goat anti-rabbit secondary antibody conjugated to horseradish peroxidase (HRP), and goat anti-mouse secondary antibody conjugated to HRP were from Nanjing Jiancheng Bioengineering Institute (Nanjing, China); RIPA protein lysis buffer, and BCA protein quantitative kit were from Thermo Fisher Scientific (Waltham, MA, USA). The human osteosarcoma cell line MG-63, was from the cell bank of the Chinese Academy of Sciences (Shanghai, China).

Cell culture. In this study, we used MG-63/siHIF- $2 \alpha(\operatorname{siHIF}-2 \alpha)$ cells and MG-63/scramble (NC) cells obtained after siRNA transfection of the human osteosarcoma cell line MG-6. Both group of cells were cultured in DMEM medium containing $10 \%$ FBS in an environment of $37^{\circ} \mathrm{C}, 5 \% \mathrm{CO}_{2}$, and saturated humidity for continuous culture. Hypoxic incubators (Thermo Fisher Scientific) with parameters set at $1 \% \mathrm{O}_{2}, 5 \% \mathrm{CO}_{2}$, and 
$94 \% \mathrm{~N}_{2}$ were used experimentally to simulate the hypoxic microenvironment within tumors.

Western blotting. MG-63 cells were cultured under hypoxia for $0,6,12$ and 24 h, respectively. MG-63 cells, NC, and siHIF-2 $\alpha$ cells were cultured under hypoxia for $24 \mathrm{~h}$. RIPA was used for cell lysis and protein extraction. A total volume of $20 \mu \mathrm{l}$ $5 \mathrm{X}$ loading buffer was added to protein samples and placed in a $100^{\circ} \mathrm{C}$ water bath for $10 \mathrm{~min}$. After $30 \mathrm{sec}$ centrifugation at $1,000 \mathrm{x}$ g, protein was separated in $12 \%$ polyacrylamide gels and transferred to PVDF membranes. The membranes were blocked in 5\% skim milk at normal temperature for $2 \mathrm{~h}$ and washed 3 times for $10 \mathrm{~min}$ in TBST. Next, membranes were treated with primary antibodies and allowed to incubate with shaking at $4^{\circ} \mathrm{C}$ overnight. Membranes were treated with secondary antibodies and incubated at normal temperature for $1 \mathrm{~h}$. Finally, membranes were treated with luminous substrate and exposed in a darkroom.

siRNA transfection. The sequences of the siRNA targeting human HIF-2 $\alpha$ were as follows: Upstream 5'-CAACCTGCA GCCTCAGTGTATC-3', downstream 5'-CACCACGTCGTT CTTCTCGAT-3'; For the siRNA with scrambled sequence as the negative control, the sequences were: upstream 5'-UUCU CCGAACGUGUCACGUTT-3', downstream 5'-ACGUGACA CGUUCGGAGAATT-3'. siRNA viruses were obtained through calcium phosphate transfection (6). A total of $1 \mathrm{ml}$ of $5 \mathrm{mg} / \mathrm{l}$ polybrene was first added to the cell medium, followed by $1 \times 10^{6}$ siRNA retrovirus particles and mixed uniformly. After $8 \mathrm{~h}$ continuous culture and replacement of the culture medium, MG-63/siHIF-2 $\alpha$ (siHIF-2 $\alpha$ ) and MG-63/scramble (NC) cells were obtained.

MTT assay. MG-63 cells were seeded in 96-well plates and treated with MTS (20 $\mu \mathrm{l} /$ well) when treated under hypoxia for 12 and $24 \mathrm{~h}$. After 1.5-2 h incubation, enzyme-linked immunosorbent assay (ELISA) (BioTek, Winooski, VT, USA) was used with the wavelength $490 \mathrm{~nm}$ to determine optical density (OD) values. Cell viability $(\%)=(\mathrm{OD}$ value of the siHIF- $2 \alpha$ group/OD value of the NC group) x $100 \%$.

Scratch and migration assay. Cells were seeded in 6-well plates. When cell density reached 90\%, $20 \mu$ l pipette tips were used to gently scratch the bottom of wells. The union of scratches was observed at 0,12 and $24 \mathrm{~h}$ and the scratch widths were measured with Image Processing and analysis in Java (Image J) $2 \mathrm{X}$ software. The relative scratch width $=$ Scratch width at the observation point/Original scratch width.

Colony formation assay. Cell populations of $1 \times 10^{3}, 2 \times 10^{3}$, $3 \times 10^{3}, 4 \times 10^{3}$ and $5 \times 10^{3}$ cells in both groups were seeded in 6 -well plates and cultured under hypoxia. Three weeks later, cells were fixed with $4 \%$ paraformaldehyde, stained with crystal violet, and observed and counted under an inverted microscope.

Statistical analysis. SPSS 20.0 software (IBM SPSS, Armonk, NY, USA) was used for statistical analysis and numerical data are presented as mean \pm standard deviation. Comparisons within groups were by t-test; comparisons among groups were
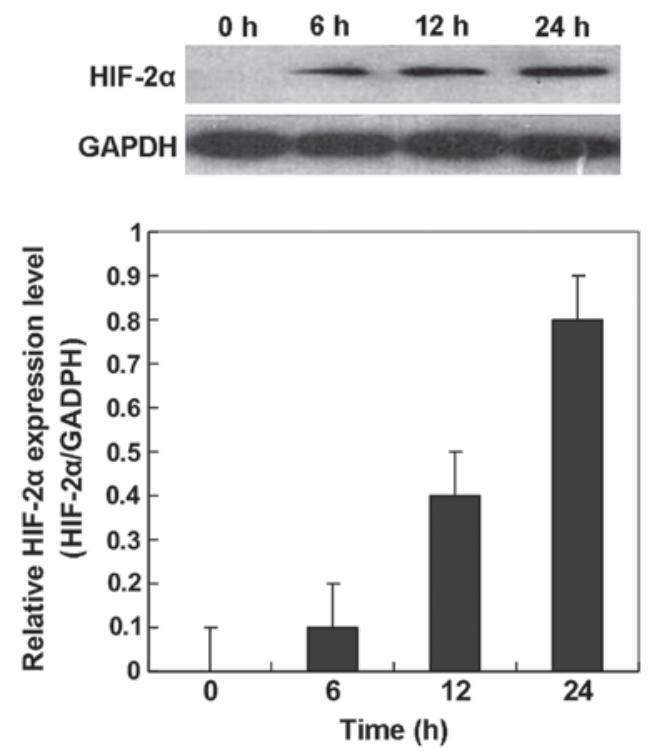

Figure 1. Comparison of the expression of HIF-2 $\alpha$ in MG-63 cells. The expression of HIF-2 $\alpha$ in osteosarcoma cells increased over time under hypoxia. The differences were statistically significant $(\mathrm{P}<0.001)$. HIF, hypoxia-inducible factor.

by one-way ANOVA; comparisons between two groups were by the Student's t-test. $\mathrm{P}<0.05$ was considered to indicate a statistically significant difference.

\section{Results}

Effect of hypoxia on HIF-2 $\alpha$ expression in MG-63 cells. To determine the effect of hypoxia on MG-63 osteosarcoma cells, we measured and found that the expression of HIF-2 $\alpha$ in osteosarcoma cells was $58.78 \pm 5.93,1,076.29 \pm 38.41,1,678.63 \pm 39.97$ and $1,861.88 \pm 41.63(\mathrm{~F}=2,187.429, \mathrm{P}<0.001)$ after culture under hypoxic conditions for 0,12 and $24 \mathrm{~h}$, respectively. The expression of HIF- $2 \alpha$ in osteosarcoma cells increased over time under hypoxia. The difference was statistically significant $(\mathrm{P}<0.001$; Fig. 1).

Viral-mediated delivery of siRNA into MG-63 cells to silence the HIF-2a gene. After delivering siRNA virus into MG-63 cells, the growth status of cells in the NC and siHIF- $2 \alpha$ groups showed no obvious changes and had relatively good fluorescence expression, as shown in Fig. 2. The expression of HIF- $2 \alpha$ in cells of the three groups were $3,189.76 \pm 126.39$ (MG-63 group), 2,928.71 \pm 68.63 (NC group) and 792.42 \pm 32.71 (siHIF-2 $\alpha$ group) $(\mathrm{F}=897.482, \mathrm{P}<0.001)$, respectively. The difference in the expression of HIF-2 $\alpha$ between the MG-63 group and the NC group was not statistically significant $(\mathrm{P}=0.387)$, although the expression in the $\mathrm{NC}$ group was significantly higher than in the siHIF-2 $\alpha$ group $(\mathrm{P}<0.001)$. The protein expression of HIF-2 $\alpha$ in the latter group was inhibited (Figs. 2 and 3).

Effect of HIF-2 $\alpha$ gene silencing on cell viability and transfer ability of MG-63 cells under hypoxic conditions. Compared with cells in the NC group, cells in the siHIF- $2 \alpha$ group experienced an obvious decline in cell viability. The relative scratch width in the NC group was notably lower than that in the 
Table I. Effect of HIF-2 $\alpha$ gene silencing on MG-63 cells under hypoxia.

\begin{tabular}{lcccc}
\hline & \multicolumn{2}{c}{ Cell viability } & \multicolumn{2}{c}{ Relative scratch width } \\
\cline { 2 - 3 } \cline { 5 - 5 } Groups & $12 \mathrm{~h}$ & $24 \mathrm{~h}$ & $12 \mathrm{~h}$ & $24 \mathrm{~h}$ \\
\hline NC & $79.00 \pm 4.91$ & $100.00 \pm 3.33$ & $0.78 \pm 0.03$ & $0.21 \pm 0.01$ \\
MG-63 & $78.04 \pm 7.21$ & $96.40 \pm 2.13$ & $0.77 \pm 0.02$ & $0.24 \pm 0.02$ \\
siHIF-2 $\alpha$ & $57.72 \pm 7.15$ & $62.33 \pm 2.89$ & $0.75 \pm 0.02$ & $0.66 \pm 0.02$ \\
T-value & $4.449^{\mathrm{a}}$ & $10.710^{\mathrm{b}}$ & $8.167^{\mathrm{b}}$ & $44.150^{\mathrm{b}}$ \\
\hline
\end{tabular}

${ }^{\mathrm{a}} \mathrm{P}<0.05,{ }^{\mathrm{b}} \mathrm{P}<0.01$. HIF, hypoxia-inducible factor.
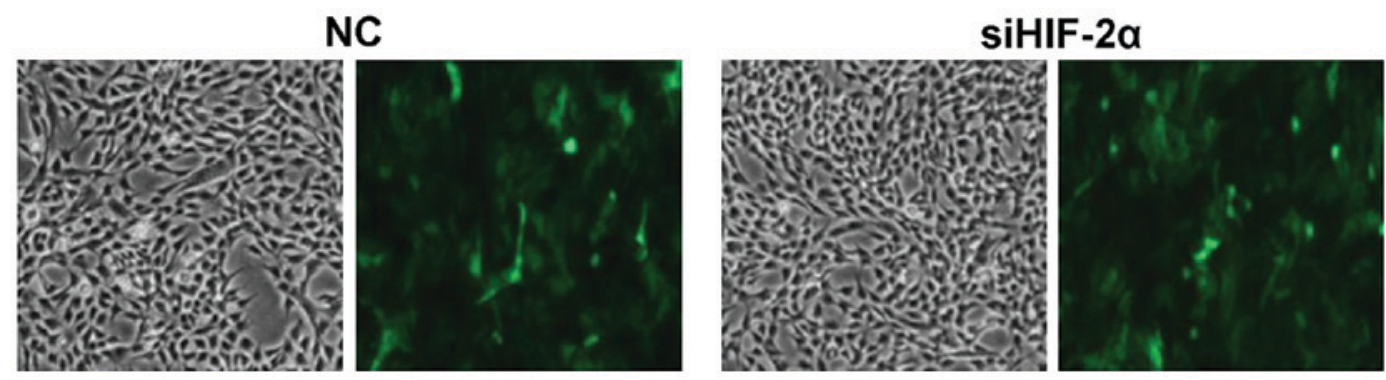

Figure 2. Mirror image and fluorogram of cells in the NC group and the siHIF-2 $\alpha$ group at a x400 magnification by an inverted microscope. HIF, hypoxia-inducible factor.

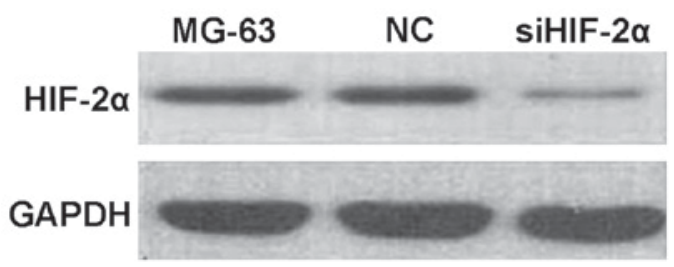

Figure 3. The expression of the HIF-2 $\alpha$ gene in each group of cells. HIF, hypoxia-inducible factor.

siHIF-2 $\alpha$ group and the difference was statistically significant $(\mathrm{P}<0.05$. The colony formation rates with different amount of cells in the NC groups were all greater than those in the siHIF- $2 \alpha$ groups $(\mathrm{P}<0.05$ or $\mathrm{P}<0.01$; Table I and Fig. $4 \mathrm{~A}-\mathrm{C})$.

Measurement of MAPK-p38 levels in each group of cells by western blotting. After $24 \mathrm{~h}$ culture under hypoxia, the levels of mitogen-activated protein kinase (MAPK)-p38 in the MG-63 and the NC groups were significantly higher than those in the siHIF-2 $\alpha$ group $(\mathrm{P}<0.05)$. This suggested that under hypoxia, HIF-2 $\alpha$ can play a regulatory role by activating the MAPK-p38 pathway (Fig. 5A and B).

\section{Discussion}

Osteosarcoma, also known as osteogenic sarcoma, is a common malignancy of the human skeletal system. Starting in mesenchymal tissue, it has a high degree of malignancy and relatively strong invasion ability. In addition, it can easily metastasize to vital organs such as the lungs and has poor prognosis. The 5-year survival rate of patients with osteosarcoma who experience lung metastasis at an early stage is generally low (8-11). This makes osteosarcoma a significant threat to human health. In China, it is estimated that the number of patients with osteosarcoma may reach 2-5 million and that the annual medical expenditure for this disease may amount to 300-500 million yuan (12). Drugs for targeted therapy of osteosarcoma are still under development (13).

The high degree of malignancy of osteosarcoma is highly connected to its tumor microenvironment. Under normal conditions, because of the proliferation of tumor cells, osteosarcoma tissue undergoes a relatively high degree of anaerobic glycolysis which can usually form a partial low-oxygen microenvironment. The formation of this kind of tumor microenvironment can further accelerate the migration and proliferation of tumor cells, which is one of the factors leading to relatively poor prognosis (14). When in the low-oxygen environment, HIF can play important regulatory roles in biological processes such as gene transcription and signal transduction (15). According to Knowles et al (16), in osteosarcoma, HIF-2 $\alpha$ can activate downstream target genes before HIF-1 $\alpha$ is activated and exert biological effects.

According to our results, the longer the incubation time of osteosarcoma cells in a low-oxygen environment, the higher the protein expression of HIF-2 $\alpha$ was. This indicated that there was a time-dependent effect between protein expression of HIF-2 $\alpha$ and hypoxia, and that the low-oxygen environment can cause MG-63 osteosarcoma cells to increase expression of HIF- $2 \alpha$ to a large extent. This observation is consistent with previous results (17).

To explore the internal biological regulatory mechanism of the osteosarcoma cell phenotype, we designed HIF-2 $\alpha$ siRNA with the goal of knocking down HIF-2 $\alpha$ gene expression, 
A

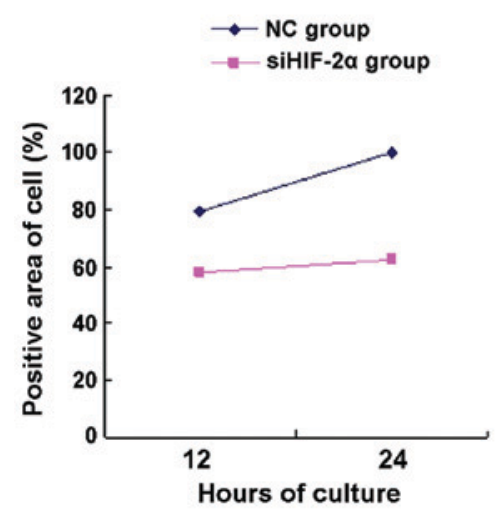

B
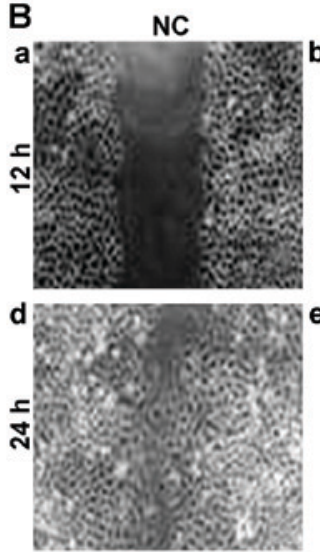

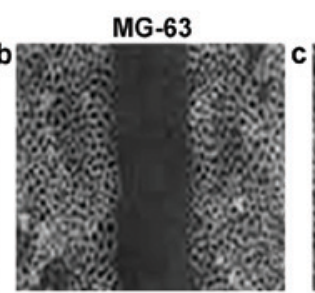

siHIF-2a
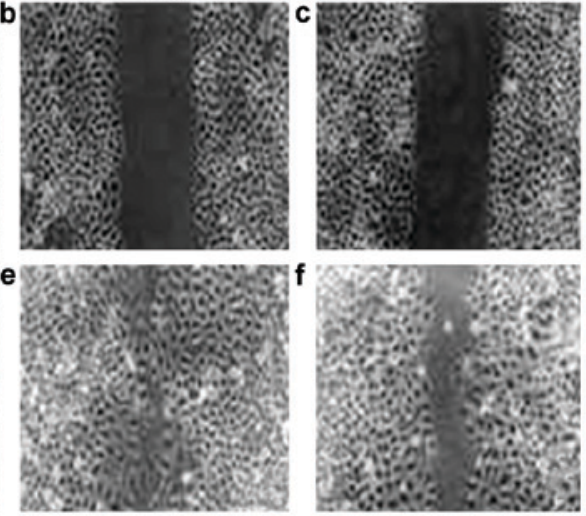

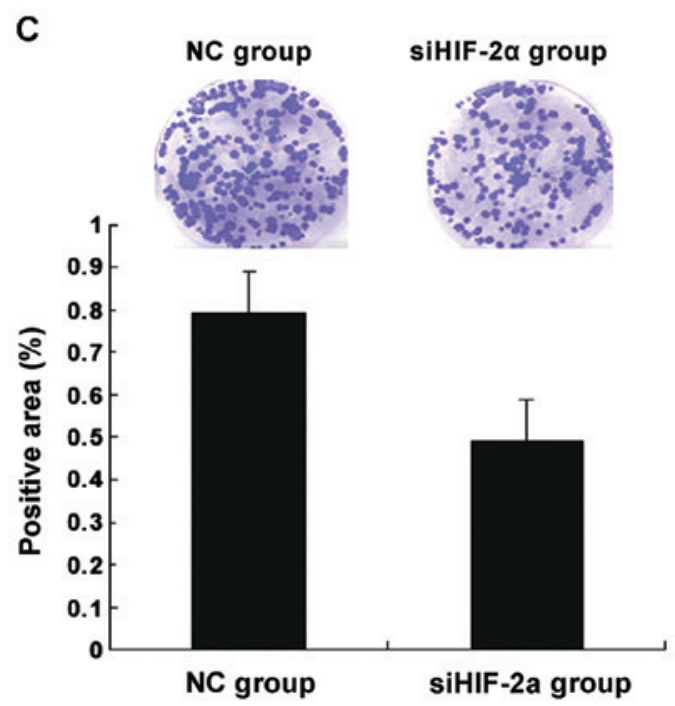

Figure 4. (A) The assessment of cell viability by MTT assay found that after $24 \mathrm{~h}$ culture, cell viability in the siHIF-2 $\alpha$ group was significantly lower than in the NC group $(\mathrm{P}<0.05)$. (B) The scratch assay showed that the relative scratch width in the NC group was significantly lower than in the siHIF-2 $\alpha$ group $(\mathrm{P}<0.05)$. (C) The colony formation rates with different amount of cells in the NC groups were all greater than those in the siHIF-2 $\alpha$ groups. HIF, hypoxia-inducible factor.

A

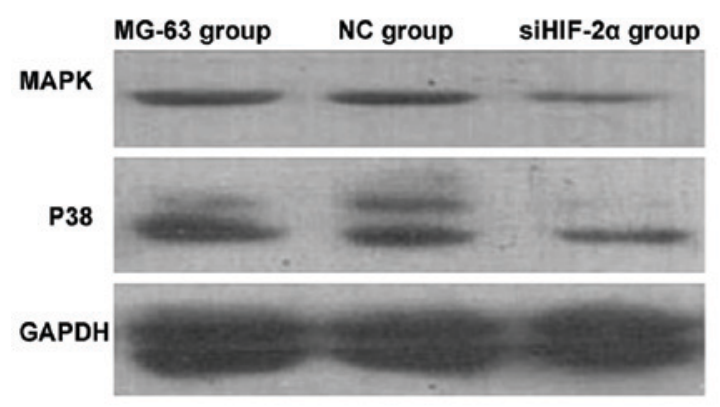

B

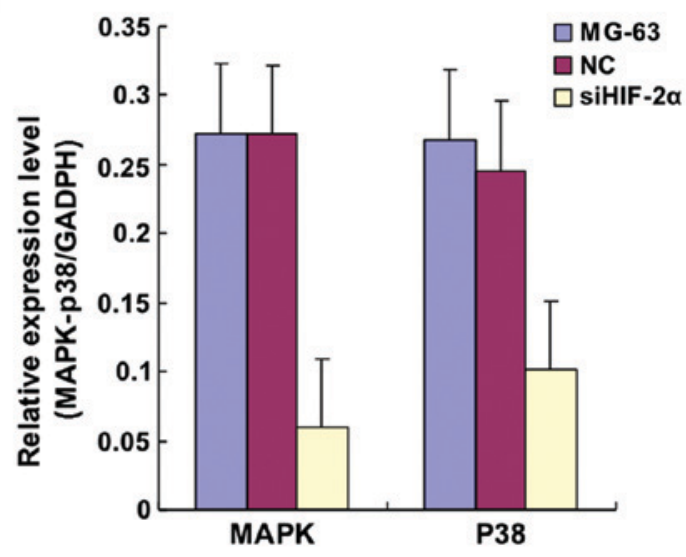

Figure 5. (A) Measurement of the expression of MAPK-p38 in each group of cells after $24 \mathrm{~h}$ culture under hypoxia. (B) Compared with cells in the MG-63 and NC groups, cells in the siHIF-2 $\alpha$ group had significantly reduced MAPK-p38 expression $(\mathrm{P}<0.05)$. MAPK, mitogen-activated protein kinase; HIF, hypoxia-inducible factor.

which is highly expressed in cancer cells. We found that siRNA significantly reduced the expression of HIF- $2 \alpha$ in osteosarcoma cells. The expression of HIF- $2 \alpha$ in the siHIF- $2 \alpha$ group was significantly lower than in the $\mathrm{NC}$ group, while the difference 
in the expression of HIF-2 $\alpha$ between the MG-63 group and the $\mathrm{NC}$ group was not statistically significant $(\mathrm{P}>0.05)$. These results indicated that siRNA can silence HIF- $2 \alpha$ in osteosarcoma cells relatively well. Moreover, MTT assay showed that after 12 to $24 \mathrm{~h}$ of treatment under hypoxia, the cell viability of the siHIF-2 $\alpha$ group was significantly lower than that of the NC group. However, in the scratch assay, the relative width of the scratch in the NC and the MG-63 group was smaller than that of the siHIF- $2 \alpha$ group. These data indicate that HIF- $2 \alpha$ gene silencing can significantly inhibit the survival and migration ability of MG-63 cells under hypoxia.

The results of the colony formation experiments showed that, regardless of the amount of siHIF- $2 \alpha$ cells seeded, their colony formation rate was much lower than that of $\mathrm{NC}$ cells. This indicated that using siRNA to silence the HIF- $2 \alpha$ gene in osteosarcoma cells can effectively suppress the proliferation of osteosarcoma cells under hypoxia. This is consistent with the idea that the HIF- $2 \alpha$ gene is highly likely to be an important gene that controls the ability of osteosarcoma cells to adapt to a low-oxygen microenvironment. The overexpression of HIF- $2 \alpha$ may facilitate the proliferation and migration of osteosarcoma cells and give rise to malignant biological behavior, and the occurrence may correlate with the lower expression of MAPK proteins after HIF- $2 \alpha$ is silenced. These findings are consistent with those of Bertout et al (13), who showed that inhibiting HIF-2 $\alpha$ can accelerate the activity of p53 signaling pathways and tumor cell apoptosis, and increase sensitivity to radiation therapy. Ben-Shoshan et al (14) showed that HIF-2 $\alpha$, as a downstream target gene of c-Myc, also has regulatory effects on the tumor cell cycle and in maintaining the increased proliferation of tumor cells under hypoxia.

MAPKs are generally not affected by outside stimuli. However, when stimulated by mitogens such as growth factors, MAPK expression increases significantly and have regulatory effects on multiple important pathophysiological processes including cellular growth, differentiation, stress, adaption to the environment, and the inflammatory response of tumor cells (18). MAPKs also play important roles in the biological growth process of tumor cells in that their expression normally correlates with the proliferation status of tumor cells, which is also the primary cause of metastasis of malignant tumor cells (19-21). The present study showed that the expression of MAPK-p38 in the si-HIF-2 $\alpha$ treated cells was lower than in the NC group, indicating that HIF- $2 \alpha$ gene silencing can inhibit angiogenesis of osteosarcoma by lowering MAPK-p38 signaling, thus inhibiting the development and progression of osteosarcoma. However, under hypoxia, the activation of MAPK signaling requires the expression of HIF- $2 \alpha$. As shown in the present study, when the HIF- $2 \alpha$ gene was silenced, given the adaptive capability of osteosarcoma cells under a low-oxygen microenvironment, the growth of osteosarcoma cells was inhibited as a result.

In conclusion, we believe the overexpression of HIF- $2 \alpha$ in osteosarcoma cells can be induced in a low-oxygen environment. HIF- $2 \alpha$ may represent a key factor in the development and progression of osteosarcoma and blocking the HIF- $2 \alpha$ signaling pathway may become an important strategy for the clinical treatment of osteosarcoma.

\section{References}

1. Vaupel P and Mayer A: Hypoxia in cancer: Significance and impact on clinical outcome. Cancer Metastasis Rev 26: 225-239, 2007.

2. Epstein AC, Gleadle JM, McNeill LA, Hewitson KS, O'Rourke J, Mole DR, Mukherji M, Metzen E, Wilson MI, Dhanda A, et al: C. elegans EGL-9 and mammalian homologs define a family of dioxygenases that regulate HIF by prolyl hydroxylation. Cell 107: 43-54, 2001.

3. Schönenberger D, Rajski M, Harlander S and Frew IJ: Vhl deletion in renal epithelia causes HIF-1 $\alpha$-dependent, HIF- $2 \alpha$-independent angiogenesis and constitutive diuresis. Oncotarget: Aug 12, 2016 (Epub ahead of print).

4. Triner D and Shah YM: Hypoxia-inducible factors: A central link between inflammation and cancer. J Clin Invest 126: 3689-3698, 2016.

5. Guo XF, Wang AY and Liu J: HIFs-MiR-33a-Twsit1 axis can regulate invasiveness of hepatocellular cancer cells. Eur Rev Med Pharmacol Sci 20: 3011-3016, 2016.

6. Nauta TD, Duyndam MC, Weijers EM, van Hinsbergh VM and Koolwijk P: HIF-2 $\alpha$ Expression regulates sprout formation into 3D fibrin matrices in prolonged hypoxia in human microvascular endothelial cells. PLoS One 11: e0160700, 2016.

7. Nepal M, Gong YD, Park YR and Soh Y: An activator of PHD2, KRH102140, decreases angiogenesis via inhibition of HIF-1 $\alpha$. Cell Biochem Funct 29: 126-134, 2011.

8. Gao Y, Li H, Ma X, Fan Y, Ni D, Zhang Y, Huang Q, Liu K, Li X, Wang L, et al: E2F3 upregulation promotes tumor malignancy through the transcriptional activation of HIF- $2 \alpha$ in clear cell renal cell carcinoma. Oncotarget: Jul 13, 2016 (Epub ahead of print).

9. Harris AL: Hypoxia - a key regulatory factor in tumour growth. Nat Rev Cancer 2: 38-47, 2002.

10. Mizobuchi H, García-Castellano JM, Philip S, Healey JH and Gorlick R: Hypoxia markers in human osteosarcoma: An exploratory study. Clin Orthop Relat Res 466: 2052-2059, 2008.

11. Kaelin WG Jr: How oxygen makes its presence felt. Genes Dev 16: 1441-1445, 2002.

12. Qu WR, Wu J and Li R: Contribution of the GSTP1 gene polymorphism to the development of osteosarcoma in a Chinese population. Genet Mol Res 15: 15, 2016.

13. Bertout JA, Majmundar AJ, Gordan JD, Lam JC, Ditsworth D, Keith B, Brown EJ, Nathanson KL and Simon MC: HIF2 $\alpha$ inhibition promotes p53 pathway activity, tumor cell death, and radiation responses. Proc Natl Acad Sci USA 106: 14391-14396, 2009.

14. Ben-Shoshan J, Schwartz S, Luboshits G, Maysel-Auslender S, Barzelay A, Polak-Charcon S, Tzahor E, Barshack I, Barak A, Levkovitch-Verbin $\mathrm{H}$, et al: Constitutive expression of HIF-1 $\alpha$ and HIF- $2 \alpha$ in bone marrow stromal cells differentially promotes their proangiogenic properties. Stem Cells 26: 2634-2643, 2008.

15. Fang Z, Tang Y, Jiao W, Xing Z, Guo Z, Wang W, Xu Z and Liu Z: Nitidine chloride induces apoptosis and inhibits tumor cell proliferation via suppressing ERK signaling pathway in renal cancer. Food Chem Toxicol 66: 210-216, 2014.

16. Knowles HJ, Schaefer KL, Dirksen U and Athanasou NA: Hypoxia and hypoglycaemia in Ewing's sarcoma and osteosarcoma: Regulation and phenotypic effects of hypoxia-inducible factor. BMC Cancer 10: 372, 2010.

17. Chatterjee B, Wolff DW, Jothi M, Mal M and Mal AK: p38a MAPK disables KMT1A-mediated repression of myogenic differentiation program. Skelet Muscle 6: 28, 2016.

18. Faber AC, Coffee EM, Costa C, Dastur A, Ebi H, Hata AN, Yeo AT, Edelman EJ, Song Y, Tam AT, et al: mTOR inhibition specifically sensitizes colorectal cancers with KRAS or BRAF mutations to BCL-2/BCL-XL inhibition by suppressing MCL-1. Cancer Discov 4: 42-52, 2014.

19. Hua S and Dias TH: Hypoxia-Inducible Factor (HIF) as a target for novel therapies in rheumatoid arthritis. Front Pharmacol 7: 184, 2016.

20. Rogers LJ, Basnakian AG, Orloff MS, Ning B, Yao-Borengasser A, Raj V and Kadlubar S: 2-amino-1-methyl-6-phenylimidazo (4,5-b) pyridine (PhIP) induces gene expression changes in JAK/STAT and MAPK pathways related to inflammation, diabetes and cancer. Nutr Metab (Lond) 13: 54, 2016.

21. Qi K, Li Y, Li X, Lei X, Wang B, Zhang L and Chu X: Id4 promotes cisplatin resistance in lung cancer through the p38 MAPK pathway. Anticancer Drugs 27: 970-978, 2016. 